\title{
La manœuvre de Nélaton
}

\section{Melaton maneuver}

\section{Martinez $\cdot$ L. Mayaud $\cdot$ I. Pozzetto Fernandez}

Reçu le 29 avril 2012 ; accepté le 4 juin 2012

(C) SFMU et Springer-Verlag France 2012

Un patient de 25 ans se présente aux urgences pour un blocage de la mâchoire inférieure en position ouverte survenu 20 min auparavant lors d'un effort de bâillement. L'examen clinique met en évidence une luxation de la mandibule inférieure. La réduction est effectuée par une manœuvre de Nélaton : le patient est installé assis dos contre le mur ; l'opérateur saisit les branches horizontales de la mandibule, les pouces appuyant vers le bas sur les molaires inférieures et les autres doigts empoignant le bord inférieur de la mandibule (Fig. 1). Ainsi l'ouverture buccale est légèrement

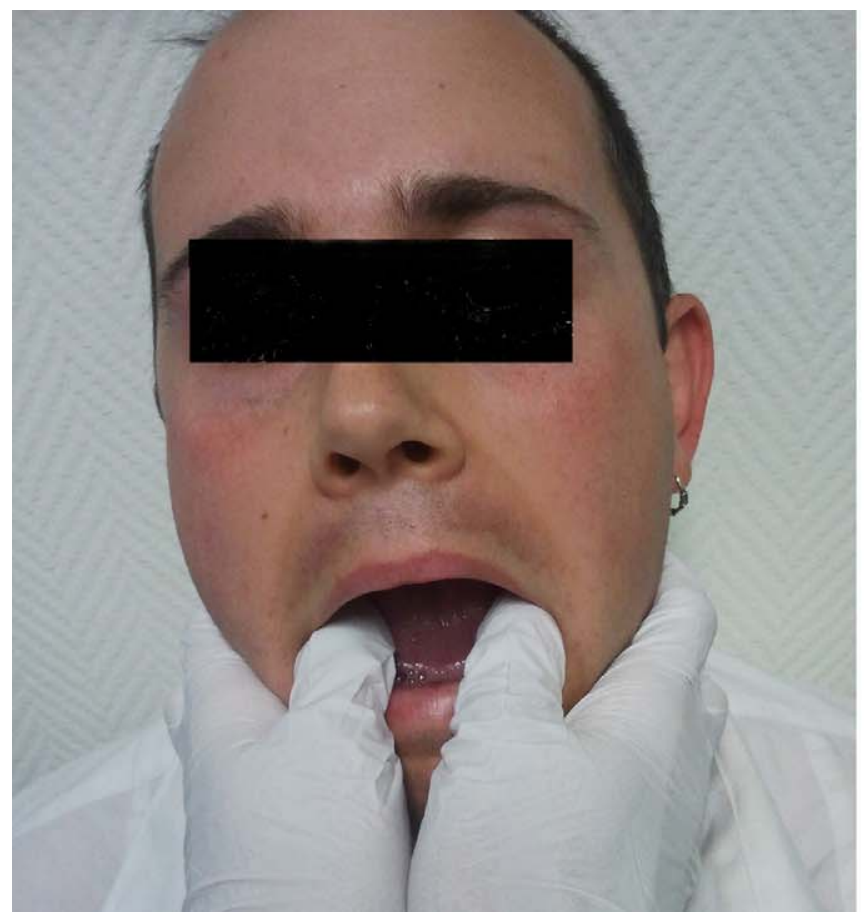

Fig. 1 Manœuvre de Nélaton. A : de face ; B : de profil

M. Martinez $(\bowtie) \cdot$ L. Mayaud · I. Pozzetto Fernandez Service urgence-Smur-UHCD, centre hospitalier de Montbrison, hôpital Beauregard, BP 219, F-42605 Montbrison cedex, France e-mail : m.martinez@ch-montbrison.fr exagérée en poussant la mâchoire vers le bas et vers l'avant afin de désenclaver les condyles. Ensuite la mandibule inférieure est poussée vers l'arrière tout en continuant de pousser vers le bas, permettant ainsi de glisser le condyle mandibulaire sous le condyle temporal : la perception d'un ressaut signe la réintégration des condyles dans les cavités glénoïdes ainsi que la possibilité pour le patient de fermer à nouveau la bouche. Le mouvement peut être réalisé simultanément ou en alternance main droite-main gauche dans la forme bilatérale [1].

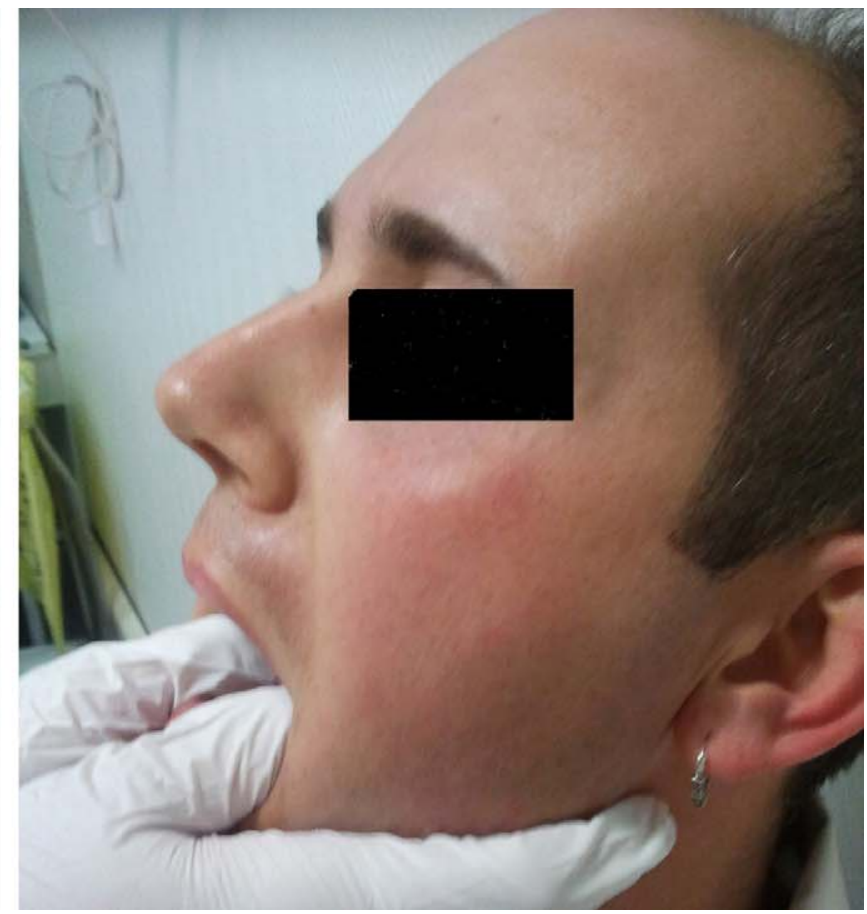

\section{Référence}

1. Chan TC, Harrigan RA, Ufberg J, Vilke GM (2008) Mandibular reduction. J Emerg Med 34:435-40 